http://doi.org/10.35784/iapgos.928

\title{
RESEARCH AND SIMULATION OF THE LOCAL NAVIGATION SYSTEM OF TERRESTRIAL MOBILE ROBOT
}

\author{
Andrii Rudyk ${ }^{1}$, Viktoriia Rudyk ${ }^{2}$, Mykhailo Matei ${ }^{2}$ \\ ${ }^{1}$ National University of Water and Environmental Engineering, Department of Automation, Electrical Engineering and Computer-Integrated Technologies, Rivne, Ukraine, \\ ${ }^{2}$ Kyiv National University of Construction and Architecture, Faculty of Automation and Information Technology, Kyiv, Ukraine
}

Abstract. The algorithm of complex information processing in the local navigation system of a terrestrial mobile robot and its physical model is developed. Experimental researches of this physical model have been carried out, as a result of which qualitative characteristics of the developed local navigation system have been determined. The trajectory of the object, based on the calculated navigation parameters, has a configuration identical to the actually passed route (adequate functioning of the system as a course indicator). The error in determining the coordinates of an offline object has value $0.012 t^{2}$ $(1.2 \mathrm{~m}$ per $10 \mathrm{~s})$ when moving linearly and $0.022 t^{2}(2.2 \mathrm{~m}$ per $10 \mathrm{~s})$ when maneuvering. The orientation angles are worked out with precision $(0.1 \div 0.3)^{\circ}$ for roll and pitch angles and $(2 \div 3)^{\circ}$ for the angle of the course. Precise characteristics of the developed physical model LNS for determining orientation angles and motion parameters MR similar to the passport serial data SINS, and in some cases due to navigation features MR show even better accuracy.

Keywords: local navigation system, mobile robot, algorithm of complex information processing, generalized Kalman filter, offline mode

\section{BADANIA I MODELOWANIE LOKALNEGO SYSTEMU NAWIGACJI NAZIEMNEJ ROBOTA MOBILNEGO}

Streszczenie. Opracowano algorytm złożonego przetwarzania informacji $w$ lokalnym systemie nawigacji naziemnego mobilnego robota $i$ jego modelu fizycznego. Przeprowadzono eksperymentalne badania tego modelu fizycznego, w wyniku których określono cechy jakościowe opracowanego lokalnego systemu nawigacji. Trajektoria obiektu, określona na podstawie obliczonych parametrów nawigacyjnych, ma konfigurację identyczna z rzeczywista przebyta trasa (system działa poprawnie jako wskaźnik). Błąd w określaniu wspótrzędnych obiektu offline wynosi 0,012t ${ }^{2}$ (1,2 $m$ w 10 s) podczas ruchu liniowego $i 0,022 t^{2}(2,2 \mathrm{~m} w 10 \mathrm{~s})$ podczas manewrowania. Kąty orientacji sa obliczane z doktadnościa $(0,1 \div 0,3)^{\circ}$ dla kątów przechylu $i$ pochylenia oraz $(2 \div 3)^{o}$ dla kata kursu. Doktadne cechy opracowanego modelu fizycznego systemu do określania katów orientacji i parametrów ruchu robota mobilnego sa podobne do danych paszportowych seryjnych BINS, a w niektórych przypadkach, ze względu na cechy nawigacji robotów mobilnych, wykazuja jeszcze lepsza dokładność.

Słowa kluczowe: lokalny system nawigacji, robot mobilny, zintegrowany algorytm przetwarzania informacji, uogólniony filtr Kalmana, tryb offline

\section{Introduction}

Navigation in mobile robotics has a number of features that do not allow to effectively use the navigation equipment of other mobile objects. Therefore, to create navigation systems for mobile robots (MR) it is necessary to use several different navigation aids with their complexation and parallel processing of information taking into account the peculiarities of the object dynamics and kinematics [2].

\section{Local navigation of mobile robots}

There are two types of navigation of autonomous MR - global and local. The main task of global navigation systems is to formulate a plan of movement on a given digital map. Local navigation systems plan and control the execution of maneuvers that are part of moving along formed route. Local navigation is a scheme for navigating autonomous MR, which determines the relative coordinates of the object and its displacement parameters on a short time interval of up to 10 minutes. The main tasks of local navigation are [4]:

- determination of relative Cartesian coordinates and parameters of MR motion;

- planning and control of MR maneuvers implementation, of which consists moving along the formed route;

- adjusting the global navigation system to determine the absolute coordinates of the MR.

An example of using a Local Navigation System (LNS) is a safe trajectory control for moving in a confined space and MR navigation in the absence of data from external navigation sources (failure of GPS based positional adjustment system). Therefore, when developing LNS, such requirements are put [12]:

- ability to determine orientation angles (course, pitch, roll) of MR and its velocity and acceleration to form the desired trajectory;

- continuous delivery of navigation information;

- accuracy of calculation of MR coordinates at short time intervals;

- system autonomy, resistance to effect of obstacle and vibration;

small overall dimensions and power consumption.
From the analysis of literary sources it is known that LNS MR can be implemented using active (inertial navigation, systems of technical vision) and passive (satellite, radio beacons and markers) navigation schemes $[3,11]$. However, most of the advantages has inertial navigation, the main advantages of which are autonomy, no influence of weather conditions and radio electronic suppression, as well as secrecy (they do not generate electromagnetic radiation that can give off the presence of MR).

\section{Structure and mathematical model of LNS}

In [12], taking into account the above requirements, the structural diagram of the LNS is presented in Fig. 1. In this structure, the IMU is used to obtain information on the six degrees of MR freedom, each of consists of three accelerometers $\left(A_{x}, A_{y}\right.$, $\left.A_{z}\right)$ and gyroscopes $\left(G_{x}, G_{y}, G_{z}\right)$ or at least six accelerometers providing the navigation system with information on angular and linear displacements of MR [13]. Because the duration of autonomous use of such a navigation system is a short time interval of up to 10 minutes [10], then the exact characteristics of the inertial sensors are less important than the requirements for the equipment of autonomous objects - the size and price characteristics, reliability, resistance to shock, vibration, etc. In this regard, MEMS inertial sensors are often used to implement such systems $[14,15]$.

IMU prints data packets on on-board computer that contain information about angular velocities and imaginary system accelerations for each axes of the linked coordinate system (LCS). The data packets are fed to the input packet processing module (IPPM), where data packet integrity take place, component partitioning, and computing module $(\mathrm{CM})$ validation useful information about angular velocities $\left(\omega_{x}, \omega_{y}, \omega_{z}\right)$ and imaginary accelerations $\left(a_{x}, a_{y}, a_{z}\right)$ system in LCS. In CM, which consists of a recalculation unit (RU) and navigation algorithm calculation modules (NACM) and orientation algorithm (OACM) occurs processes of filtering and calculating the navigation parameters of MR - angles of course, pitch and roll $(\alpha, \beta, \chi)$ and passed distance, speed and acceleration $(s, v, n)$ [9]. The utilized IMU in LNS was a custom made device. 


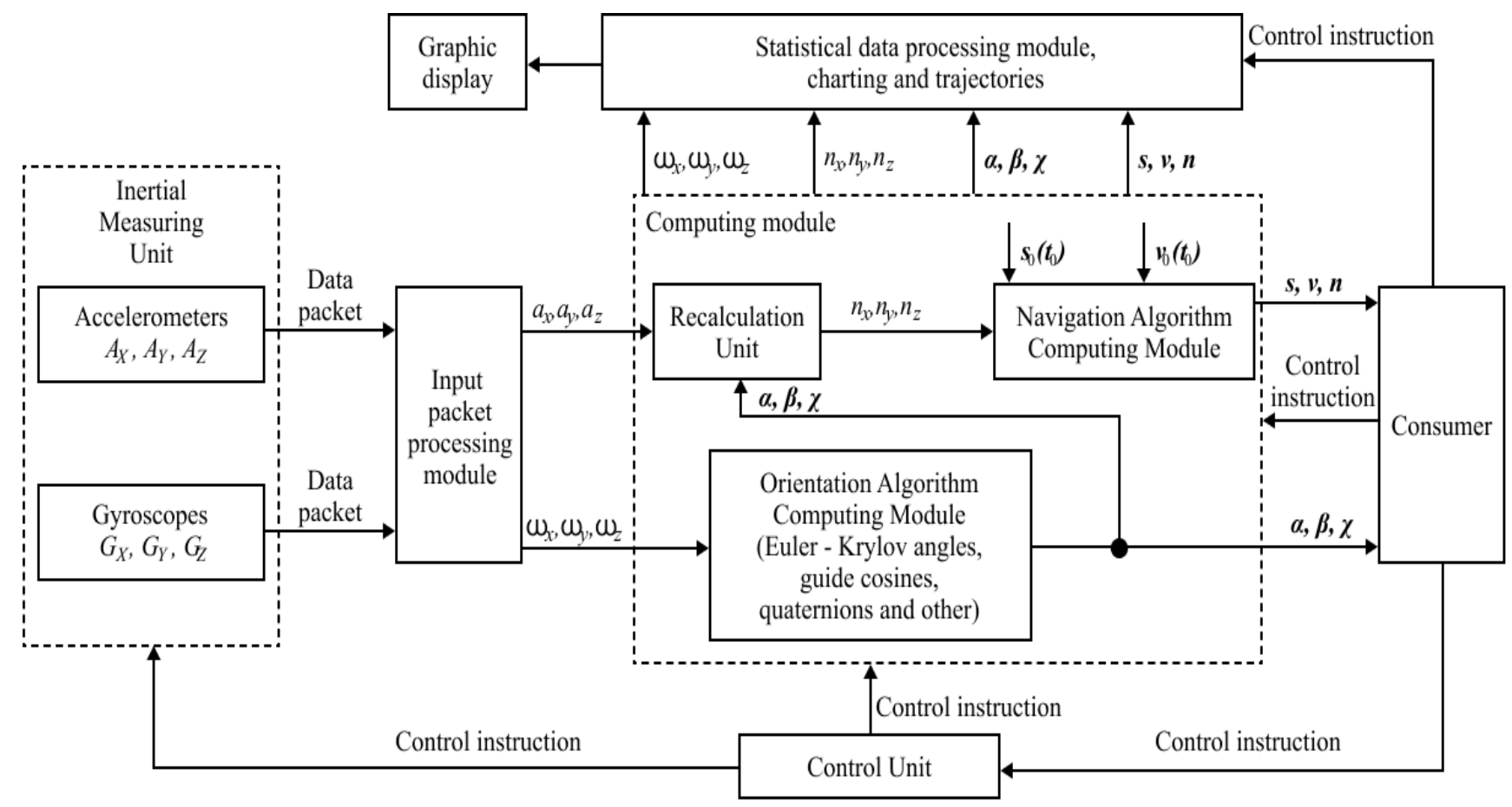

Fig. 1. Structural diagram of the local navigation system

Obtained navigation information, depending on the $\mathrm{CM}$ settings and the control commands from the consumer, can be issued in a different form to the graphical display using module of statistical data processing, charting and trajectories. The information from the IMU sensors in the processed IPPM form is stored in the CM memory for subsequent playback and data analysis [1]. The LNS control unit that controls the operation of the IMU and CM can be commanded by the consumer.

When moving MR, most of the wheels, we will take into account a number of features that affect the definition of navigation parameters: no lateral wear; small ranges of changes pitch and roll angles within short time intervals; the independence of the angular velocity of rotation about the vertical axis MR from the angular velocities of rotation about other axes; small linear speed of MR movement. With these features in mind, we will use the following mathematical model MR in the developed autonomous LNS:

$$
\begin{aligned}
& \dot{\alpha}=\omega_{z} ; \quad \dot{\beta}=\omega_{x} \cos \chi+\omega_{z} \sin \chi ; \quad n_{x}=a_{x} \cos \chi+a_{z} \sin \chi ; \\
& \dot{\chi}=\omega_{y} ; \quad n_{y}=a_{x} \sin \beta \sin \chi+a_{y} \cos \beta-a_{z} \sin \beta \cos \chi ; \\
& n_{z}=-a_{x} \cos \beta \sin \chi+a_{y} \sin \beta+a_{z} \cos \beta \cos \chi-g ; \\
& v\left(t_{1}\right)=v_{0}\left(t_{0}\right)+\int_{t_{0}}^{t_{1}} n_{y} d t ; \quad s\left(t_{1}\right)=s_{0}\left(t_{0}\right)+\int_{t_{0}}^{t_{1}} \int_{t_{0}}^{t_{1}} n_{y} d t
\end{aligned}
$$

where $n_{x}, n_{y}, n_{z}$-projections of true acceleration on the axis of the moving trajectory coordinate system (MTCS); $v_{0}\left(t_{0}\right), s_{0}\left(t_{0}\right)-$ initial velocity values and coordinates at time $t_{0}$ (initial conditions).

To account for the accumulation of SINS integration errors [17] we supplement the system mathematical model with equations that relate the measured values of the angular velocities and the components of MR imagined acceleration with their true values $\omega_{j}^{m}=\omega_{j}+\varepsilon_{j}$ and $a_{j}^{m}=a_{j}+\psi_{j}$, where $\omega_{j}^{m}, a_{j}^{m}$-values of angular velocities and components of the imagined acceleration of MR, that are determined by sensors; $\omega_{j}, a_{j}$ - the true values of the angular velocities and the components of the imagined acceleration MR; $\varepsilon_{j}, \psi_{j}$ - measurement errors; $j=\{x, y, z\}$.

\section{Development of the algorithm of complex information processing}

Because all measured and observed quantities are related by nonlinear dependencies, to determine the vector of the MR state by the vector of measurement of inertial sensors at each moment of time is used nonlinear filtering algorithm - generalized Kalman filter (GKF) [5]. In this case, the task of estimating the vector state $x_{i}$ comes down to filtering the Markov sequence $x_{i}=\Phi_{i}\left(x_{i-1}\right)+\vartheta_{i}$ by the measurements taken at each $i$-th time $y_{i}=\varphi_{i}\left(x_{i}\right)+\lambda_{i}$ in the Gaussian nature of generating noises $\vartheta_{i}$ and measurement errors $\lambda_{i}$. Function $\Phi_{i}\left(x_{i-1}\right)$ characterizes the dynamics of the state vector change, and the function $\phi_{i}\left(x_{i}\right)$ - measurement vector connection $y_{i}$ with him.

GKF is based on a Gaussian approximation of posterior density in the Taylor series expansion of functions $\Phi_{i}\left(x_{i-1}\right)$ and $\varphi_{i}\left(x_{i}\right)\left(x_{l 1}, x_{l 2}-\right.$ points of linearization):

$$
\begin{gathered}
\Phi_{i}\left(x_{i-1}\right) \approx \Phi_{i}\left(x_{l 1}\right)+\frac{\partial \Phi_{i}\left(x_{l 1}\right)}{\partial x_{i-1}^{T}}\left(x_{i-1}-x_{l 1}\right) \\
\phi_{i}\left(x_{i}\right) \approx \phi_{i}\left(x_{l 2}\right)+\frac{\partial \phi_{i}\left(x_{l 2}\right)}{\partial x_{i}^{T}}\left(x_{i}-x_{l 2}\right)
\end{gathered}
$$

As points of linearization in (1) and (2) is used vector state estimation of the previous and posterior estimation of the current steps: $x_{l 1}=\tilde{x}_{i-1}, x_{l 2}=\tilde{x}_{i / i-1}$.

Thus, the mathematical apparatus of one iteration of the GKF algorithm consists in the sequential determination of the following quantities:

- aposteriori evaluation of the state vector

$$
\tilde{x}_{i / i-1}=\Phi_{i}\left(x_{l 1}\right)+\frac{\partial \Phi_{i}\left(x_{l 1}\right)}{\partial x_{i-1}^{T}}\left(\tilde{x}_{i-1}-x_{l 1}\right)
$$

- covariance matrix of the state vector posterior estimation

$$
P_{i / i-1}\left(x_{l 1}\right)=\frac{\partial \Phi_{i}\left(x_{l 1}\right)}{\partial x_{i-1}^{T}} P_{i-1}\left(\frac{\partial \Phi_{i}\left(x_{l 1}\right)}{\partial x_{i-1}^{T}}\right)^{T}+Q_{i}
$$

where $Q_{i}$ - matrix of intensity of generating noises; 
- covariance matrix of the current state vector estimator

$$
P_{i}\left(x_{l 1}, x_{l 2}\right)=\left(\left(P_{i / i-1}\left(x_{l 1}\right)\right)^{-1}+\left(\frac{\partial \phi_{i}\left(x_{l 2}\right)}{\partial x_{i}^{T}}\right)^{T} R_{i} \frac{\partial \phi_{i}\left(x_{l 2}\right)}{\partial x_{i}^{T}}\right)^{-1}
$$

- Kalman filter gain coefficient

$$
K_{i}\left(x_{l 1}, x_{l 2}\right)=P_{i}\left(x_{l 1}, x_{l 2}\right)\left(\frac{\partial \phi_{i}\left(x_{l 2}\right)}{\partial x_{i}^{T}}\right)^{T} R_{i}
$$

where $R_{i}$-measurement noise intensity matrix;

- current assessment of the state vector

$$
\tilde{x}_{i}=\tilde{x}_{i / i-1}+K_{i}\left(x_{l 1}, x_{l 2}\right)\left(y_{i}-\phi_{i}\left(x_{l 2}\right)-\frac{\partial \phi_{i}\left(x_{l 2}\right)}{\partial x_{i}^{T}}\left(\tilde{x}_{i / i-1}-x_{l 2}\right)\right)
$$

On the basis of the mathematical model of Local Navigation System, the type used in (3)-(7) matrices and vectors. The measurement vector is thus shaped $y_{i}=\left(\omega_{x i}, \omega_{y i}, \omega_{z i}, a_{x i}, a_{y i}, a_{z i}\right)^{T}$, and a 21-dimensional state vector consist of values from mathematical model equations, changing velocity of the filtered values $\ddot{\alpha}, \ddot{\beta}, \ddot{\chi}$ and $\ddot{n}_{x}, \ddot{n}_{y}, \ddot{n}_{z}$, which are necessary to determine the dynamics matrix $\Phi_{i}\left(x_{i-1}\right)$. Because information about these parameters is not available, they are modeled by generating noise in the form of Markov stationary processes [6-8]. Finally, the system dynamics matrix $\Phi_{i}\left(\tilde{x}_{i-1}\right)$, link of the measurement vector to the system state vector $\varphi_{i}\left(\tilde{x}_{i / i-1}\right)$ covariance $Q_{i}$ generating noises $\vartheta_{i}$ and covariances $R_{i}$ measurement noise $\lambda_{i}$ described by (8)-(11). In this formulas $E_{j}=\exp \left(-\Delta t / \tau_{j}\right), \tau_{j}-$ time constants for modeling the rate of change of filtered quantities that characterize the possible frequency of their change; $\Delta t=t_{i}-t_{i-1}-$ discretization period; $Q_{j}-$ the intensity of white noise by which the rate of change of the filtered values is simulated; $N_{j}$-intensity of measurement noise.

The following is a list of parameters that must be defined or specified to enable the use of the resulting matrices in the generalized Kalman filter filtering algorithm [16]: the initial values of the state vector $x_{0}$ and covariance matrices $P_{0}$; the value of the discretization period $\Delta t$; value of time constants of simulated Markov processes $\tau_{j}$; intensity of generating noises $Q_{j}$ and measurement noise $N_{j}$. The optimal values of these parameters are selected in the research of the physical model.

$$
\begin{aligned}
& \Phi_{i}\left(\tilde{x}_{i-1}\right)=\left|\begin{array}{cccccccccccccccccccccc}
1 & \Delta t & 0 & 0 & 0 & 0 & 0 & 0 & 0 & 0 & 0 & 0 & 0 & 0 & 0 & 0 & 0 & 0 & 0 & 0 & 0 \\
0 & 1 & \Delta t & 0 & 0 & 0 & 0 & 0 & 0 & 0 & 0 & 0 & 0 & 0 & 0 & 0 & 0 & 0 & 0 & 0 & 0 \\
0 & 0 & E_{\alpha} & 0 & 0 & 0 & 0 & 0 & 0 & 0 & 0 & 0 & 0 & 0 & 0 & 0 & 0 & 0 & 0 & 0 & 0 \\
0 & 0 & 0 & 1 & \Delta t & 0 & 0 & 0 & 0 & 0 & 0 & 0 & 0 & 0 & 0 & 0 & 0 & 0 & 0 & 0 & 0 \\
0 & 0 & 0 & 0 & 1 & \Delta t & 0 & 0 & 0 & 0 & 0 & 0 & 0 & 0 & 0 & 0 & 0 & 0 & 0 & 0 & 0 \\
0 & 0 & 0 & 0 & 0 & E_{\beta} & 0 & 0 & 0 & 0 & 0 & 0 & 0 & 0 & 0 & 0 & 0 & 0 & 0 & 0 & 0 \\
0 & 0 & 0 & 0 & 0 & 0 & 1 & \Delta t & 0 & 0 & 0 & 0 & 0 & 0 & 0 & 0 & 0 & 0 & 0 & 0 & 0 \\
0 & 0 & 0 & 0 & 0 & 0 & 0 & 1 & \Delta t & 0 & 0 & 0 & 0 & 0 & 0 & 0 & 0 & 0 & 0 & 0 & 0 \\
0 & 0 & 0 & 0 & 0 & 0 & 0 & 0 & E_{\chi} & 0 & 0 & 0 & 0 & 0 & 0 & 0 & 0 & 0 & 0 & 0 & 0 \\
0 & 0 & 0 & 0 & 0 & 0 & 0 & 0 & 0 & 1 & 0 & 0 & 0 & 0 & 0 & 0 & 0 & 0 & 0 & 0 & 0 \\
0 & 0 & 0 & 0 & 0 & 0 & 0 & 0 & 0 & 0 & 1 & 0 & 0 & 0 & 0 & 0 & 0 & 0 & 0 & 0 & 0 \\
0 & 0 & 0 & 0 & 0 & 0 & 0 & 0 & 0 & 0 & 0 & 1 & 0 & 0 & 0 & 0 & 0 & 0 & 0 & 0 & 0 \\
0 & 0 & 0 & 0 & 0 & 0 & 0 & 0 & 0 & 0 & 0 & 0 & 1 & \Delta t & 0 & 0 & 0 & 0 & 0 & 0 & 0 \\
0 & 0 & 0 & 0 & 0 & 0 & 0 & 0 & 0 & 0 & 0 & 0 & 0 & E_{n_{x}} & 0 & 0 & 0 & 0 & 0 & 0 & 0 \\
0 & 0 & 0 & 0 & 0 & 0 & 0 & 0 & 0 & 0 & 0 & 0 & 0 & 0 & 1 & \Delta t & 0 & 0 & 0 & 0 & 0 \\
0 & 0 & 0 & 0 & 0 & 0 & 0 & 0 & 0 & 0 & 0 & 0 & 0 & 0 & 0 & E_{n_{y}} & 0 & 0 & 0 & 0 & 0 \\
0 & 0 & 0 & 0 & 0 & 0 & 0 & 0 & 0 & 0 & 0 & 0 & 0 & 0 & 0 & 0 & 1 & \Delta t & 0 & 0 & 0 \\
0 & 0 & 0 & 0 & 0 & 0 & 0 & 0 & 0 & 0 & 0 & 0 & 0 & 0 & 0 & 0 & 0 & E_{n_{z}} & 0 & 0 & 0 \\
0 & 0 & 0 & 0 & 0 & 0 & 0 & 0 & 0 & 0 & 0 & 0 & 0 & 0 & 0 & 0 & 0 & 0 & 1 & 0 & 0 \\
0 & 0 & 0 & 0 & 0 & 0 & 0 & 0 & 0 & 0 & 0 & 0 & 0 & 0 & 0 & 0 & 0 & 0 & 0 & 1 & 0 \\
0 & 0 & 0 & 0 & 0 & 0 & 0 & 0 & 0 & 0 & 0 & 0 & 0 & 0 & 0 & 0 & 0 & 0 & 0 & 0 & 1
\end{array}\right|
\end{aligned}
$$

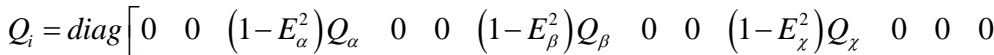

$$
\begin{aligned}
& \left.0 \quad\left(1-E_{n_{x}}^{2}\right) Q_{n_{x}} \quad 0 \quad\left(1-E_{n_{y}}^{2}\right) Q_{n_{y}} \quad 0 \quad\left(1-E_{n_{z}}^{2}\right) Q_{n_{z}} \quad 0 \quad 0 \quad 0\right] \\
& \phi_{i}\left(\tilde{x}_{i / i-1}\right)=\left|\begin{array}{c}
\frac{\dot{\beta}_{i / i-1}-\dot{\alpha}_{i / i-1} \sin \chi_{i / i-1}}{\cos \chi_{i / i-1}}+\varepsilon_{x i / i-1} \\
\dot{\chi}_{i / i-1}+\varepsilon_{y i / i-1} \\
\dot{\alpha}_{i / i-1}+\varepsilon_{z i / i-1} \\
n_{x i / i-1} \cos \chi_{i / i-1}+\left(n_{y i / i-1} \sin \beta_{i / i-1}-\left(n_{z i / i-1}+g\right) \cos \beta_{i / i-1}\right) \sin \chi_{i / i-1}+\psi_{x i / i-1} \\
n_{y i / i-1} \cos \beta_{i / i-1}+\left(n_{z i / i-1}+g\right) \sin \beta_{i / i-1}+\psi_{y i / i-1} \\
n_{z i / i-1} \sin \chi_{i / i-1}+\left(n_{y i / i-1} \sin \beta_{i / i-1}-\left(n_{z i / i-1}+g\right) \cos \beta_{i / i-1}\right) \cos \chi_{i / i-1}+\psi_{z i / i-1}
\end{array}\right| \\
& R_{i}=\operatorname{diag}\left[\begin{array}{llllll}
N_{\alpha} & N_{\beta} & N_{\chi} & N_{n_{x}} & N_{n_{y}} & N_{n_{z}}
\end{array}\right]
\end{aligned}
$$




\section{Investigation of the physical model of LNS}

For experimental tuning of LNS parameters and verification of the proposed algorithm for calculation accuracy of MR navigation parameters, a physical model of the system was implemented, which is a combination of IMU (MEMS chip triaxial accelerometer and magnetometer type LSM303DHL and triaxial gyroscope type L3G42000D) and a GPS receiver with a built-in antenna and designed to determine the coordinates of the object and the orientation angles of the object. Using such a system without a GPS receiver is similar to autonomous mode.

To implement the functions Computing module, Input packet processing module and Control unit (Fig. 1) has been developed software that performs such functions in accordance with the block diagram LNS: receiving and processing IMU data packets; calculation of navigational parameters of MR by the implemented algorithm of information processing; saving the MR motion parameters obtained from the IMU during the experiment, in Statistical data processing module, charting and trajectories (SDPMCT) for further reproduction, processing and analysis of results.

Based on the work results, the authors developed two options for the implementation of inertial orientation microsystems based on the Kalman filter: for the MR control circuit (Fig. 2a) and for the backup orientation system (Fig. 2b). These orientation systems have been successfully tested and have shown stable operation during long-term operation (5 hours or more). The technical characteristics of orientation systems are shown in table 1.

Table 1. Technical characteristics of inertial orientation microsystems

\begin{tabular}{|c|c|c|}
\hline \multirow[b]{2}{*}{ Characteristic } & \multicolumn{2}{|c|}{ Value } \\
\hline & $\begin{array}{c}\text { Based on Kalman } \\
\text { filter }\end{array}$ & Backup system \\
\hline Supply voltage, V & $7 \ldots 12$ & $9, \pm 15$ \\
\hline Supply current, A & 0.35 & $\begin{array}{c}0.5(9 \mathrm{~V}) \\
0.1( \pm 15 \mathrm{~V})\end{array}$ \\
\hline $\begin{array}{l}\text { Measured angular velocities } \\
\text { range, } \% \mathrm{~s}\end{array}$ & \pm 400 & \pm 100 \\
\hline Measured accelerations range, $g$ & $0 \ldots 6$ & $0 \ldots 10$ \\
\hline $\begin{array}{l}\text { Angle detection range: } \\
- \text { course }^{\circ} \\
- \text { pitch, }^{\circ} \\
- \text { roll, }^{\circ} \\
\end{array}$ & $\begin{array}{c}0 \ldots 360 \\
\pm 90 \\
\pm 180\end{array}$ & $\begin{array}{c}- \\
\pm 90 \\
\pm 180\end{array}$ \\
\hline $\begin{array}{l}\text { The maximum error course angle } \\
\text { determining: } \\
\text { - linearly moving, }{ }^{\circ} \\
\text { - when maneuvering, }{ }^{\circ}\end{array}$ & $\begin{array}{c}1.85 \\
2.8\end{array}$ & $\begin{array}{l}- \\
-\end{array}$ \\
\hline $\begin{array}{l}\text { The maximum error pitch angle } \\
\text { determining: } \\
\text { - linearly moving, }{ }^{\circ} \\
\text { - when maneuvering, }{ }^{\circ}\end{array}$ & $\begin{array}{c}1.9 \\
2.95\end{array}$ & $\begin{array}{l}2.0 \\
3.1\end{array}$ \\
\hline $\begin{array}{l}\text { The maximum error roll angle } \\
\text { determining: } \\
\text { - linearly moving, }{ }^{\circ} \\
\text { - when maneuvering, }{ }^{\circ}\end{array}$ & $\begin{array}{l}2.1 \\
2.8\end{array}$ & $\begin{array}{l}2.2 \\
2.9\end{array}$ \\
\hline Weight, gram & 100 & 750 \\
\hline Overall dimensions, $\mathrm{mm}$ & $50 \times 50 \times 50$ & $80, \varnothing 118$ \\
\hline
\end{tabular}

Experimental researches of the physical model were conducted in a brick room with a minimum number of metal surfaces and in the open space (uniform asphalt pavement). The length of the MR trajectory was up to $80 \mathrm{~m}$ when moving in a straight line and up to $35 \mathrm{~m}$ when maneuvering.

In the GPS receiver algorithmically compensates systematic errors from the receiver clock offset relative to the system scale and from ionospheric and tropospheric signal delays on the propagation path. However, there are random errors due to the influence of internal noise of the receiver, which in the conditions of "open sky" lead to random errors in determining the coordinates with a standard deviation (2-3) m. Deterioration of the accuracy of satellite measurements due to the "shading" of the sky by tall buildings and multi-beam signal propagation leads to an increase in standard deviations of the coordinates up to $7 \mathrm{~m}$ and the modulus of absolute speed up to $0.25 \mathrm{~m} / \mathrm{s}$.

At the rectilinear movement of MR (at a constant angle of a course) exact characteristics are better, than at maneuvering. However, over time, the error in determining the longitudinal component of velocity and coordinates gradually increases and reaches the characteristic errors of GNSS [8].

When maneuvering, any nonlinearity of the trajectory shape is characterized by a change in the course angle. Significant changes in the course angle when turning lead to an increase of errors in determining the coordinates of the MR. When maneuvering on a trajectory with the shape of a circle, the course angle changes linearly, and the standard deviation of the error of determining the coordinates is almost constant.

In the researches, the maximum time of satellite loss was 5 minutes with a minimum duration of the initial full-constellation correction of 1 minute. Therefore, the question of the initial installation of SINS is relevant.
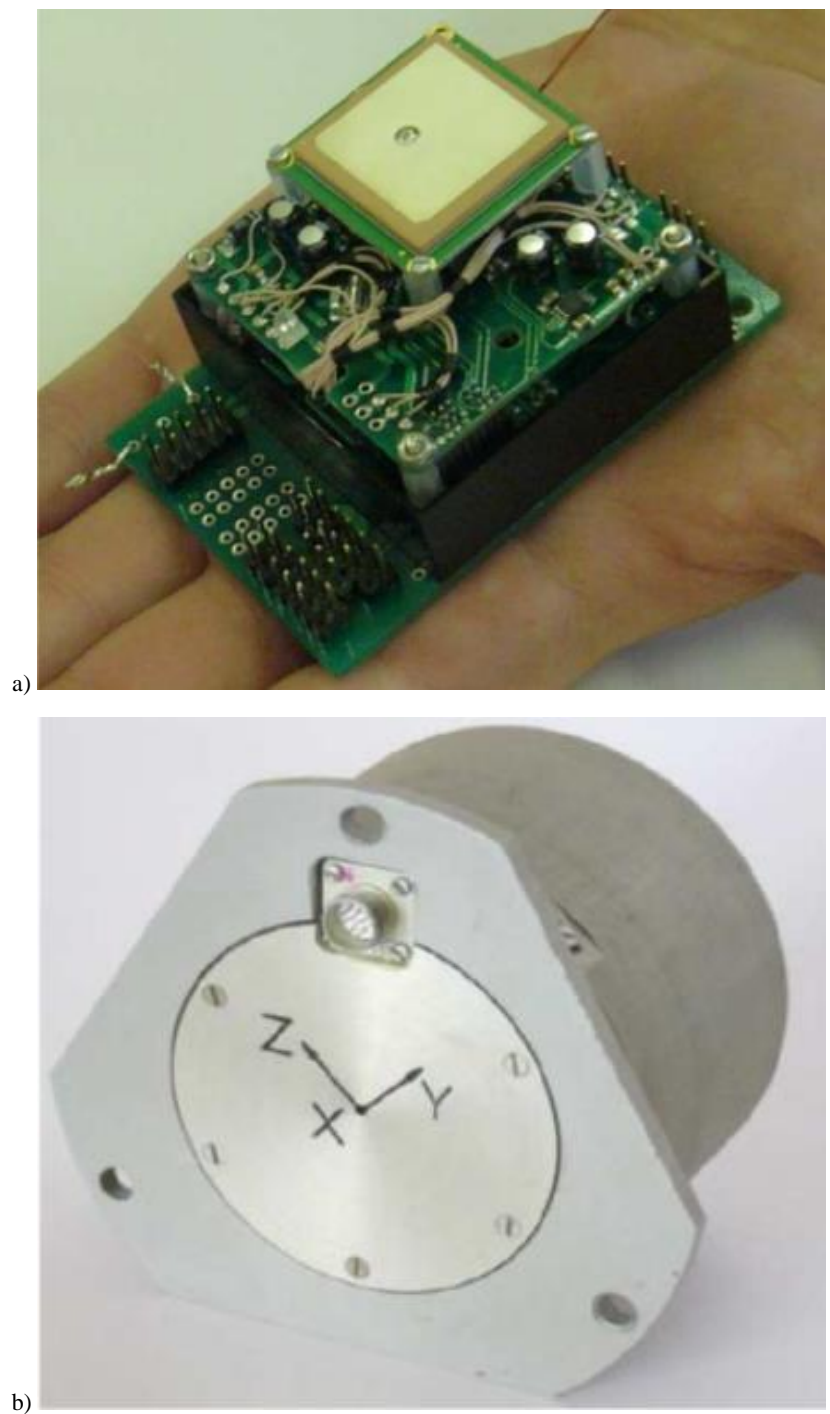

Fig. 2. Implementation of inertial orientation microsystems based on Kalman filter for the MR control circuit (a) and for the backup orientation system (b)

The results of experimental researches of the physical model are shown in Fig. 3 and Fig. 4, which allows us to draw conclusions about the following qualitative characteristics of the developed LNS:

- trajectory of the object based on the calculated navigation parameters, has a configuration identical to the actually completed route (adequate LNS operation as a course pointer); 
- the error of determining the coordinates of the LNS object in offline has a value $0.012 t^{2}(1.2 \mathrm{~m}$ per $10 \mathrm{~s})$ when moving linearly and $0.022 t^{2}(2.2 \mathrm{~m}$ per $10 \mathrm{~s})$ when maneuvering;

- refinement of the MR orientation angles is accurate $(0.1 \div 0.3)^{\mathrm{o}}$ for roll and pitch angles and $(2 \div 3)^{\mathrm{o}}$ for the angle of the course;

- accurate characteristics of the developed physical model LNS for determining the orientation angles and MR motion parameters are similar to the serial SINS passport data, and in some cases at the expense of navigation features MR show slightly better accuracy.
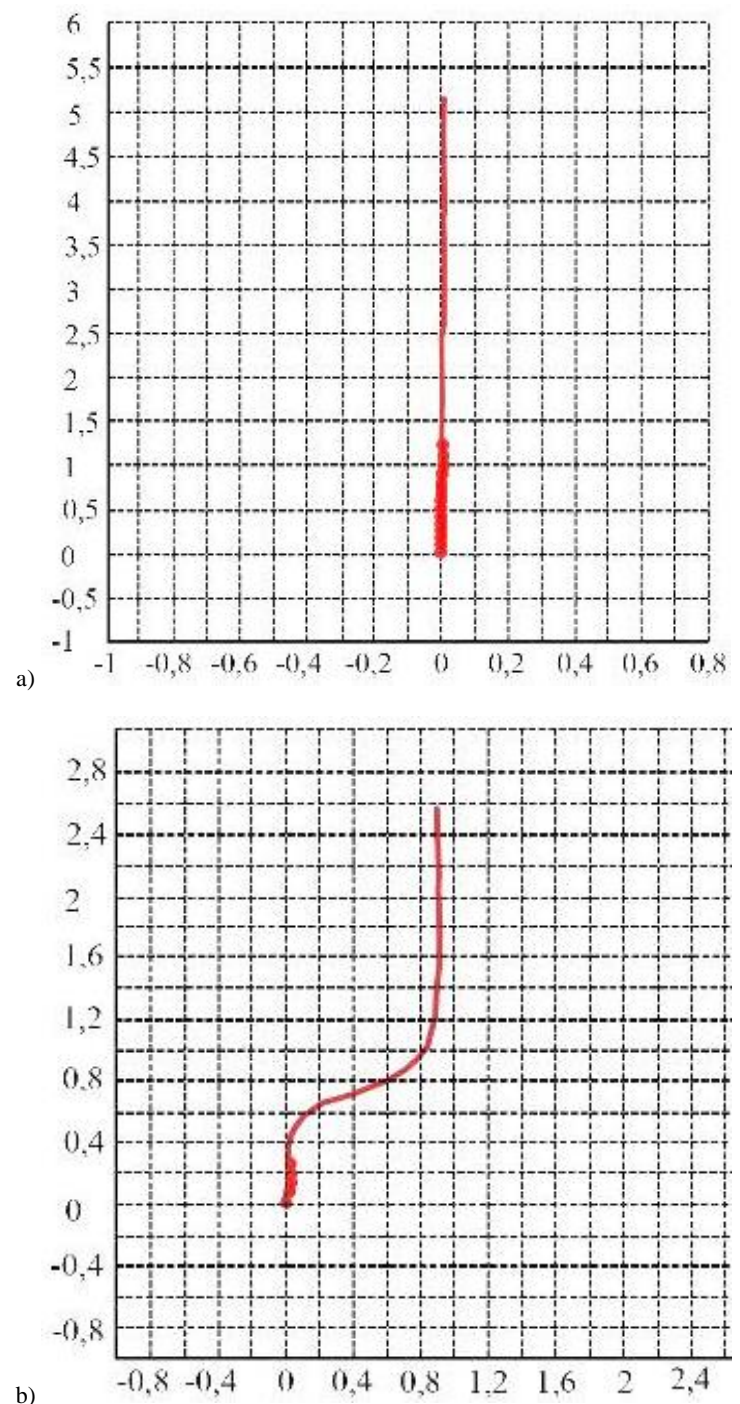

Fig. 3. Actual object trajectories obtained by a physical model in the case of straightline displacement (a) and maneuvering $(b)$

According to certain qualitative characteristics of the physical model we can make the following conclusions about using the developed LNS:

- autonomous use of LNS indoors is possible at short time intervals $(5 \div 10) \mathrm{s}$; in open areas, autonomous using time is up to $60 \mathrm{~s}$, and the provided accuracy is comparable to accuracy of GPS;

- the use of this LNS in the navigation system is acceptable and has some advantages over the known analogues.
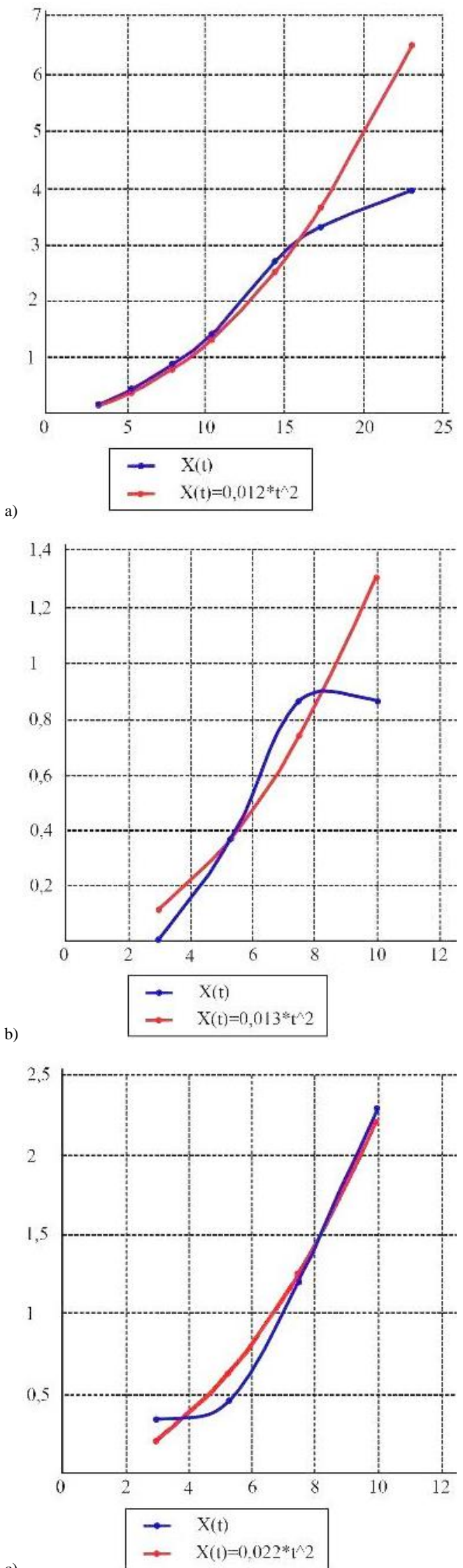

Fig. 4. Dependencies of object coordinate errors (observed deviation of the robo actual route from the measured IMU readings) over time (blue curves) and approximating functions (red curves) when moving linearly (a) and when maneuvering $(b, c)$ 


\section{Conclusions}

The results of investigations of the physical model of the developed LNS confirm the possibility of its use in the navigation complex of terrestrial MR. The system provides accuracy in determining the coordinates of the object and its orientation angles and it allows you to use the developed system as a stand-alone system to control maneuvers when moving the MR along a safe route for short intervals, and in combination with other navigation devices (GPS, odometers, rangefinders, etc.). In the future it is planned to improve the mathematical model and algorithm of information and software processing to calculate the navigation parameters of an object to improve the accuracy of the system, as well as the practical implementation of the advanced system and integrate it into the navigation complex for terrestrial MR.

\section{References}

[1] Arvanitakis I., Giannousakis K., Tzes A.: Mobile robot navigation in unknown environment based on exploration principles. Control Applications (CCA), IEEE Conference on. IEEE, 2016, 493-498.

[2] Corke P.: An introduction to inertial and vision sensing. International Journa of Robotics Research 6(26), 2007, 519-535.

[3] Farrell J.A.: Aided Navigation: GPS with High Rate Sensors. McGraw-Hill, New York 2008

[4] Gang L., Wang J.: PRM path planning optimization algorithm research. Wseas Transactions on Systems and Control 11, 2016, 81-86.

[5] Grewal M.S., Weill L.R., Andrews A.P.: Global Position Systems, Inertial Navigation and Integration. John Wiley \& Sons, New York 2001.

\begin{abstract}
Prof. D.Sc.(Technical) Andrii Rudyk
e-mail: a.v.rudyk@nuwm.edu.ua

Professor of Automation, electrical engineering and computer integrated technologies Department, National University of Water and Environmental Engineering, Rivne, Ukraine.

The main scientific direction - development of methods and devices for measuring motion parameters of mobile robots. Author over 150 scientific papers, including 12 patents.
\end{abstract}

http://orcid.org/0000-0002-5981-3124

Student Viktoriia Rudyk
e-mail: vikka2612@gmail.com
Student of Kyiv National University of Construction
and Architecture, Faculty of Automation and
Information Technology, Kyiv, Ukraine.
Engaged in scientific mathematical simulation of
various processes, computer techniques and computer
technologies, programming. Author over 20 scientific
papers.
http://orcid.org/0000-0001-8014-1054

[6] Grewal M.S., Andrews A.P.: Kalman filtering: theory and practice using MATLAB. J. Wiley \& Sons. Inc., New York 2001

[7] Groves P.D.: Principles of GNSS, Inertial and Multisensor Integrated Navigation Systems. Artech House 2008.

[8] Ingle V.K., Proakis J.G.: Digital Signal Processing Using MATLAB. V.4. PWS Publishing Company, Boston 2009.

[9] Ko D.W. Kim Y.N., Lee J.H., Suh I.H. A scene-based dependable indoor navigation system. Intelligent Robots and Systems (IROS), IEEE/RSJ International Conference on. IEEE, 2016, 1530-1537.

[10] Kvasnikov V.P., Rudyk A.V.: Practical estimation of errors of single-channel strapdown inertial navigation system on MEMS sensors in a short time interval. Visnyk of Ukraine Engineering Academy 1, 2017, 98-105.

[11] Rudyk A.V.: Methods for evaluating the spatial position of objects. Integrated Intelligent Robotics (IIRTC-2016), 2016, 31-33.

[12] Rudyk A.V.: Development of a local navigation system for a terrestrial mobile robot. Modern problems of radio electronics, telecommunications and instrumentation, Vinnytsia 2017, 75-76.

[13] Rudyk A.V.: Comparative analysis of the accuracy characteristics of classical and accelerometric inertial navigation systems. Measurement, control and diagnostics in technical systems, Vinnytsia 2017, 209-210.

[14] Rudyk A.V.: Analysis of the errors of MEMS accelerometers by the Allan variation method. Visnyk of Zhytomyr State Technological University. Series: Technical Sciences 1, 2017, 100-109.

[15] Titterton D.H., Weston J.L.: Strapdown Inertial Navigation Technology Stevenage: Institution of Electrical Engineers York, 2004

[16] Wang L., Zhao L., Huo G., Li R., Hou Z., Luo P., et al.: Visual semantic navigation based on deep learning for indoor mobile robots. Complexity, 2018. Article ID: 1627185 .

[17] Weiping Jiang, Li Wang, Xiaoji Niu, Zhang Quan, Zhang Hui, Tang Min: High-precision image aided inertial navigation with known features: observability analysis and performance evaluation. Sensors 14(10), 2014, 19371-19401.

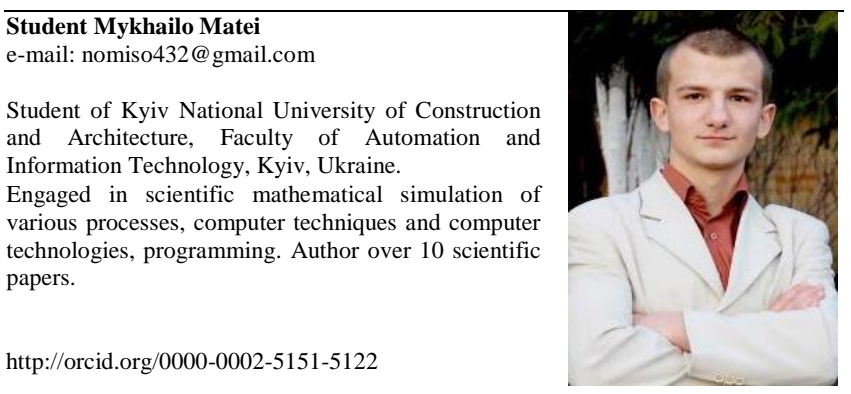

otrzymano/received: 22.12 .2019 przyjęto do druku/accepted: 26.06 .2020 